\title{
A Study of Midarm Circumference and Chest Circumference as a Predictor of Low Birth Weight
}

\author{
Mamta Nikhurpa', Sucheta Munshi², Dipti Shah ${ }^{3}$ \\ ${ }^{1}$ Postgraduate Resident, Department of Pediatrics, B J Medical College, Ahmedabad, Gujarat, ${ }^{2}$ Associate Professor, Department of Pediatrics, B J Medical College, \\ Ahmedabad, Gujarat, ${ }^{3}$ Assistant Professor, Department of Pediatrics, B J Medical College, Ahmedabad, Gujarat.
}

\section{Abstract}

Background: $60-80 \%$ of neonatal deaths are due to low birth weight (LBW <2500 g) in developing countries. Aim \& Objective: The objectives of this study was to identify a suitable anthropometric surrogate and to identify LBW babies in the resource limited settings like

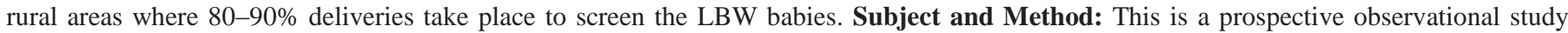
conducted in department of pediatrics of tertiary care hospital and medical college of western India. A total of 519 newborns were studied by random sampling method. BW and other anthropometric measurements were taken within $24 \mathrm{~h}$ of birth. Result: Mean birth weight significantlyincreases with increasing value of anthropometric measurement, all key anthropometric parameters were significantly correlated to each other. The correlation with birth weight is more for chest circumference (0.58) than mid upper arm circumference (0.54). Conclusion: CC is the better measurement to identify low birth-weight babies. Measurement of both MUAC and CC is of little additional value in predicting LBW babies. Chest circumference is a simple, quick, and valid screening tool for identifying LBW neonates in a community setting where there are problems of nonavailability of weighing scales.

Keywords: Low birth weight, Newborn, Anthropometric measurement, Mid-arm circumference, Chest circumference.

Corresponding Author: Dr. Mamta Nikhurpa, Postgraduate Resident, Department of Pediatrics, B J Medical College, Ahmedabad, Gujarat, Kamal Nilay, Surabhi Colony phase-2, Malli Bamori, Haldwani, District-Nainital, Pincode- 263139, Uttarakhand.

Email: mamtanikhurpa389@gmail.com

Received: January 2020

Accepted: January 2020

\section{Introduction}

Birth weight has been accepted as the most important reliable index and indicator of neonatal morbidity and mortality ${ }^{[1]}$ About $15 \%$ or 20.3 million of all live birth worldwide are estimated to be low birth weight (LBW) $<2500 \mathrm{gm}$ accounting for $60-80 \%$ of all neonatal death. However, most of the times weight at birth is not recorded because almost $80 \%$ of the deliveries in India take place at home or at rural health centre where weighing scales tend to be either non available or defective. ${ }^{[2,3]}$ Newborn are most vulnerable during the first hours and days of life, yet this critical window is being missed. Data indicate that in least developed countries, only about half $(54 \%)$ of newborn are weighed at birth as proper weighing machines are not available at rural hospitals. Regionalization and strengthening of rural health care services along with intact timely referral of at risk newborn is a challenge in our country. In view of improving outcome as timely referral is key for better survival of low birth weight newborn this study aim for identifying anthropometric measurement at birth as surrogates for birth weight. ${ }^{[4,5]}$ Significant correlations between birth weight and anthropometric measurements have been reported by various research workers. Using these parameters simple devices to estimate birth weight and screen for low birth weight can be done at peripheral health centre by community health workers and timely identification and prompt referral of at-risk newborn to higher centre can significantly improve child survival.

\section{Subjects and Methods}

This is a prospective observational study conducted in department of pediatrics of tertiary care hospital and medical college of western India for a period of 24 month from October 2015 to October 2017.

\section{Inclusion criteria}

All inborn and outborn delivered newborns less than $2.5 \mathrm{~kg}$ birth weight admitted within 48 hour of life have been included.

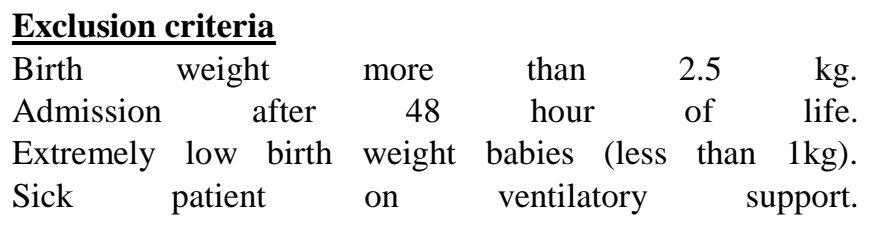


Major congenital malformation.

\section{Method}

All new born under inclusion criteria were selected by simple random sampling. In each case detailed history, birth history, relevant obstetric history, socioeconomic status, weight at birth, anthropometric examination was done within 24 hour of birth.

Patient's weight, was measured naked at birth or within 48 hours. Measurements were performed with digital electronic weighing scale ebsa-20 to the nearest of $5 \mathrm{gm}$. The machine was calibrated at regular intervals. Mid upper arm circumference (MUAC) was measured at the mid-point of the left upper arm between the tip of acromian process and olecranon process with a fiber glass measuring tape to the nearest of $0.1 \mathrm{~cm}$. Chest circumference (CC) was measured at the level of nipple by a fibre glass measuring tape to the nearest $0.1 \mathrm{~cm}$ at the end phase of expiration. Length and head circumference were measured after 24 hours /within 48 hours of birth. The length was recorded with an infantometer to the nearest $0.1 \mathrm{~cm}$ with the baby supine, knees fully extended and soles of feet held firmly against and head touching the fixed board. The head circumference was measured at the maximum circumference of the head (i.e. occipito-frontal) with a non-stretchable tape to the nearest $0.1 \mathrm{~cm}$. All parameters were measured twice and an average of the two values was recorded. However in case if there was large discrepancy between the two readings (defined as $>5 \%$ ) then repeat measurements were taken. Continuous variables were reported as mean and standard deviation and comparison of continuous variables was performed using independent sample t-test. Receiver operating characteristic (ROC) curves were used to evaluate the accuracy of different anthropometric measurements with LBW.

The collected data was analyzed using statistical software SPSS version 11.5 and descriptive and analytic (one-way analysis of variance (ANOVA), t-test) statistics and confidence interval $95 \%$, $\mathrm{p}$ value $<0.05$ was considered significant.

\section{Results}

The present study was a prospective observational study carried out on 519 LBW infants admitted to NICU of a tertiary care hospital, over period of two years.

During the study period, 3857 were LBW babies admitted accounting for incidence amongst the indoor patients of $24.74 \%$, and after applying the exclusion criteria 519 patients were included in our study .

Of 519 babies, 298 babies (57\%) were male and 221 babies (43\%) were female. Among 1000 newborns, $795(79.5 \%)$ were normal BW (NBW) and 205 (20.5\%) babies were LBW.

In present study number of preterm newborn were 270 (52\%) and higher than term 140 (27\%) and post-term newborn 109 (21\%)

Among distribution of weight maximum number of newborn $388(75 \%)$ were in birth weight range of $1500-2000 \mathrm{gm}$ compare to $42(8 \%)$ in $1000-1500 \mathrm{gm}$ and only $89(17 \%)$ were in $2000-2400$ gm range this group of newborn require only level-1 care which can be given at home/PHC level by mother under guidance of AWW, ASHA worker, ANM or LHW.

Birth weight of 519 newborn studied ranged from 1100 to $2400 \mathrm{gm}$, with a mean of $1817 \mathrm{gm}$ and standard deviation of $242 \mathrm{gm}$. The mean chest circumferences (CC), mid upper arm circumference (MUAC) were $28.27 \pm 2.1 \mathrm{~cm}$ and $7.57 \pm 0.7 \mathrm{~cm}$ respectively.

Mean birth weight was $1817.77 \mathrm{gm}$ with a standard deviation of $242 \mathrm{gm}$, mean chest circumference and mean mid-upper arm circumference was $29.2 \pm 2.6 \mathrm{~cm}$ and $9.3 \pm 1.1 \mathrm{~cm}$ respectively. No significant difference in anthropometric measurement was observed for both sex.

Table 1: Relationship between birth weight and other anthropometric measurements

\begin{tabular}{|c|c|c|c|c|}
\hline Variable & $\begin{array}{l}\text { Total } \\
\text { cases } \\
(519)\end{array}$ & $\begin{array}{l}\text { Mean birth } \\
\text { weight (gm) }\end{array}$ & SD & $F$ (p value) \\
\hline \multicolumn{5}{|c|}{ Chest circumference (CC) } \\
\hline$<26$ & 17 & 1657.29 & 240 & \multirow{5}{*}{$67.6(0.00)$} \\
\hline $26-29.9$ & 376 & 1748.12 & 211 & \\
\hline $30-31.9$ & 74 & 1962.70 & 146 & \\
\hline $32-33.9$ & 33 & 2141.51 & 103 & \\
\hline $34-38$ & 19 & 2238.88 & 114 & \\
\hline \multicolumn{5}{|c|}{ Mid upper arm circumference (MUAC) } \\
\hline$<7$ & 43 & 1558.23 & 200 & \multirow{4}{*}{$58.4(0.00)$} \\
\hline $7-8.9$ & 443 & 1815.50 & 216 & \\
\hline $9-10.9$ & 28 & 2169.28 & 102 & \\
\hline $11-12$ & 5 & 2400.00 & 0 & \\
\hline
\end{tabular}

Mean birth weight increases with increasing value of all anthropometric measurement, which indicates that birth weight correlates with chest circumference and mid-upper arm circumference.

Table 2: Correlation Of Birth Weight With MUAC And CC

\begin{tabular}{|c|c|c|c|c|c|c|}
\hline Birth wt & $\mathrm{CC}$ & $\mathbf{F}$ & P value & MUAC & $\mathbf{F}$ & p value \\
\hline $\begin{array}{l}1000- \\
1499 \mathrm{gm}\end{array}$ & $\begin{array}{l}27.06 \\
\pm 1.35\end{array}$ & \multirow{3}{*}{72} & \multirow{3}{*}{0.0000} & $7.25 \pm 0.35$ & \multirow{3}{*}{97} & \multirow{3}{*}{0.0000} \\
\hline $\begin{array}{l}1500- \\
1999 \mathrm{gm}\end{array}$ & $\begin{array}{l}27.78 \\
\pm 1.43\end{array}$ & & & $7.34 \pm 0.27$ & & \\
\hline $\begin{array}{l}2000- \\
2499 \mathrm{gm}\end{array}$ & $\begin{array}{l}29.67 \\
\pm 2.59\end{array}$ & & & $8.12 \pm 0.99$ & & \\
\hline
\end{tabular}

o Between weight $1000-1499$ gm , total newborn are 40, with mean birth weight of 1368.57 gm corresponds with, chest circumference range of $27.06 \pm 1.35 \mathrm{~cm}$, mid upper arm circumference range of $7.25 \pm 0.35 \mathrm{~cm}, \mathrm{p}$ value 0.000 (statistically significant ) 


\section{Nikhurpa et al; Predictor of Law Birth Weight}

o Between weight 1500 - 1999gm, total newborn are 310 , with mean birth weight of 1729.85 gm corresponds with, chest circumference range is $27.77 \pm 1.43 \mathrm{~cm}$, mid upper arm circumference range of $7.34 \pm 0.27 \mathrm{~cm}, \mathrm{p}$ value 0.000 (statistically significant)

o Between weight 2000 - 2499gm , total newborn are 169 , with mean birth weight of 2018.29 gm corresponds with, chest circumference range is $29.67 \pm 2.59 \mathrm{~cm}$, mid upper arm circumference range of $8.12 \pm 0.99 \mathrm{~cm}, \mathrm{p}$ value 0.000( statistically significant)

Table 3: Matrix of zero order correlation coefficient between birth weight and other anthropometric measurement

\begin{tabular}{|c|c|c|c|}
\hline Anthropometry & Weight & $\begin{array}{l}\text { Chest } \\
\text { circumference }\end{array}$ & $\begin{array}{l}\text { Mid arm } \\
\text { circumference }\end{array}$ \\
\hline WT (gm) & 1 & 0.58 & 0.54 \\
\hline $\mathrm{CC}(\mathrm{cm})$ & 0.58 & 1 & 0.66 \\
\hline MUAC $(\mathrm{cm})$ & 0.54 & 0.66 & 1 \\
\hline
\end{tabular}

Matrix of zero-order correlation coefficient shows that all measurement significantly correlate with each other. The correlation with birth weight is more for chest circumference (0.58)than mid upper arm circumference (0.54)

Therefore chest circumference is better surrogate for low birth weight as compare to mid-upper arm circumference.

Table 4: Simple regression equation for estimating birth weight of newborn

\begin{tabular}{|l|l|l|l|}
\hline Anthropometry & $\begin{array}{l}\text { Regression } \\
\text { equation }\end{array}$ & P value & Adjusted R2 \\
\hline CC $(\mathrm{cm})$ & $\begin{array}{l}\text { BWT }=-52.68+ \\
66.15(C C)\end{array}$ & 0.000 & 0.34 \\
\hline MUAC $(\mathrm{cm})$ & $\begin{array}{l}\text { BWT }=441.62 \\
+181.63 \\
\text { MUAC) }\end{array}$ & 0.000 & 0.29 \\
& $\begin{array}{l}\text { BWT }=\text { birth weight, CC=chest circumference, MUAC }=\text { mid upper arm } \\
\text { circumference }\end{array}$ \\
\hline
\end{tabular}

Multiple regression equation also showed that $\mathrm{CC}$ alone explained the variation of birth-weight by $90 \%$, and the additional use of MUAC not significantly improves the prediction of birth-weight.

\section{Discussion}

In this study, a total of 519 babies were enrolled with a mean BW of $1817 \mathrm{gm}$. In the present study, $24.74 \%$ babies were of LBW compared to $48.7 \%, 41 \%, 55.27 \%$, and $17.56 \%$ in studies conducted by Kaur et $\mathrm{al}^{[6]}$, Dhar et al. ${ }^{[7]}$ Kumar et al. ${ }^{[8]}$ and Ezeaka et al. ${ }^{[9]}$ Relationship between birth weight and other anthropometric measurements showed that mean birth weight significantly increases with increasing value of all anthropometric measurement, which further strengthens correlation of birth weight with chest circumference and mid-upper arm circumference.
Relationship of birth weight with anthropometric measurement significantly comparable ( $\mathrm{p}$ value 0.000 ) with Kaur M.et $\mathrm{al}^{[6]}$ study. Matrix of zero-order correlation coefficient between birth weight and other anthropometric measurement of newborn at birth shows that all measurement significantly correlate with each other. So we can predict the birth weight using anyone of these measurement.

The correlation with birth weight is more for chest circumference (0.58) than mid upper arm circumference (0.54) This correlation falls with close proximity with Kaur M. et $\mathrm{al}^{6}$ study where correlation was highest with chest circumference (0.95) and less with mid-upper arm circumference $(0.93)$ \& Bhargava et al. ${ }^{[3]}$ where correlation was maximum for chest circumference $(r=0.8696)$ and mid-arm circumference $(\mathrm{r}=0.8110) \mathrm{CC}$ is the better measurement to identify low birth-weight infants. Multiple regression equation also showed that $\mathrm{CC}$ alone explained the variation of birth-weight by $90 \%$, and the additional use of MUAC not significantly improves the prediction of birthweight. Moreover, $\mathrm{CC}$ is more replicable than that of MUAC as firstly it is simpler to measure as identification of the nipple line is easier making measurement more operationally feasible than that of mid-arm circumference. Secondly, the findings suggest that measurement of both MUAC and CC is of little additional value in predicting LBW babies.

\section{Conclusion}

Birth weight is a reliable and sensitive indicator for predicting the immediate or later outcome of a newborn child.The study was conducted with the objective of comparing anthropometric measurements as a screening tool for LBW neonates.Many hospital-based studies have reported the utility of anthropometric measurements to screen for LBW neonates. ${ }^{[3,10-13]}$ The current study shows that chest circumference is a simple, quick, and valid screening tool for identifying LBW neonates in a community setting where there are problems of nonavailability of weighing scales. Chest circumference appears as the most appropriate surrogate measure for birth weight. Similar findings were reported by other studies. ${ }^{[14,15]}$ Also, CC can be feasible and convenient for screening low birth weight and timely identification and prompt referral of at-risk newborn to higher centre which can significantly improve child survival.

\section{References}

1. Kumar V, Datta N. Birth weight as an indicator of health. Ind Paediatr. 1984; 21:113-118.

2. McCormick M C. The contribution of low birth weight to infant morbidity and childhood mortality. N Engl J Med.1985; 312:82-90.

3. Bhargava S K,Ramji S, Kumar A. Manmohan, Marwah J, Sachdeva HPS. Mid arm and chest circumference at birth as predictors of low birth weight and neonatal mortality in the community. Brit Med 


\section{Nikhurpa et al; Predictor of Lau Birth Weight}

J.1985; 291:1617-1619.

4. Kulkarni A P, Sathe P V. Relationship between birth weight and anthropometric measurement of newborn. Indian J Community Med. 1993; 18:141- 8. Int J Med Health Sci. Jan 2014,Vol-3;Issue-1 6

5. Mullany L C, Darmstadt G L, Khatry S K, Leclerq S C, Tielsch J M. Relationship between the surrogate anthropometric measurements, foot length and chest circumference and birth weight among newborns of Sarlahi Nepal. Eur J ClinNutr. 2007; 61:40-6.

6. Kaur M, Singh Z, Kaur G, Goyal LD. Correlation of birth weight with other anthropometric measurements in new born. Indian J Basic Appl Med Res 2013; 2:870-9.

7. Dhar B, Mowlah G, Naha SR, Islam N. Birth-weight status of newborns and its relationship with other anthropometric parameters in a public maternity hospital in Dhaka, Bangladesh. J Health Popul Nutr 2002;20:36-41.

8. Kumar S, Jaiswal K, Dabral M, Malhotra AK, Verma BL. Calf circumference at birth: A screening method for detection of low birth weight. Indian J Community Health 2012;24:336-41

9. Ezeaka VC, Egri-Okawaji MT, Renner JK, Grange AO. Anthropometric measurements in the detection of low birth weight infants in Lagos. Niger Postgrade Med J 2003;10:168-172.

10. Ramaiya C, Msamanga G, Massawe S, Mpanju W, Ngwalle E. Newborn's arm circumference as a screening tool of low birth weight in Temeke District, Dar es Salaam, Tanzania. Trop Geogr Med. 1994;46:318-321.

11. Taksande A, Vilhekar KY, Chaturvedi P, Gupta S, Deshmukh P.
Predictor of low birth weight neonates by anthropometry. J Trop Pediatr. 2007;53:420-423.

12. Sood SL, Saiprasad GS, Wilson CG. Mid arm circumference at birth: a screening method for detection of low birth weight. Indian Pediatr. 2002;39:838-842.

13. Sreeramareddy CT, Chuni N, Patil R, Singh D, Shakya B. Anthropometric surrogates to identify low birth weight Nepalese newborns: a hospital-based study. BMC Pediatr. 2008;8:16.

14. Kapoor SK, Kumar G, Anand K. Use of mid-arm and chest circumferences to predict birth weight in rural north India. J Epidemiol Community Health. 1996;50:683-686.

15. World Health Organization. Use of a simple anthropometric measurement to predict birth weight: WHO collaborative study of birth surrogates. Bull World Health Organ. 1993;71:157-163.

Copyright: () the author(s), 2020. It is an open-access article distributed under the terms of the Creative Commons Attribution License (CC BY 4.0), which permits authors to retain ownership of the copyright for their content, and allow anyone to download, reuse, reprint, modify, distribute and/or copy the content as long as the original authors and source are cited.

How to cite this article: Nikhurpa M, Munshi S, Shah D. A Study of Midarm Circumference and Chest Circumference as a Predictor of Low Birth Weight. Asian J. Clin. Pediatr. Neonatol.2020;8(1):05-08.

DOI: dx.doi.org/10.47009/ajcpn.2020.8.1.2

Source of Support: Nil, Conflict of Interest: None declared. 